$\checkmark$ life, from speech perception and production to experiencing and memorizing what he terms the "best moments of life". Here he presents an elegant selection of the often confusing, sometimes contradictory academic literature, with a clear emphasis on his own work and that of collaborators and mentors such as functional "Scienceshould neuroanatomist explore how perceived time affects everyday activities, as well as how everyday activities influence our perception of time."

Bud Craig and psychologist and neuroscientist Ernst Pöppel.

In the last two chapters, Wittmann advances a theory of how temporal perception is directly linked to the self-con-

sciousness of bodily states. His idea is grounded in the observation that during timing tasks, the brain's insular cortex (a part of the cerebral cortex associated with the integration of physiological input such as heartbeat) is active. Wittmann suggests that the heart might act as an 'internal clock', because accuracy in counting heartbeats correlates with how accurately someone can estimate the duration of an interval. Although there are correlational studies that link sensing heartbeat with timing accuracy, Wittmann unfortunately ignores prominent alternative proposals for the brain mechanisms that underlie the internal clock. For example, there is ample evidence that corticostriatal circuits - neural pathways that link the basal ganglia with the neocortex - are key to the accurate timing of duration in the range of seconds to minutes. Such work is better covered in other books or special journal issues on the neurobiology of timing (for example, H. Merchant and V. de Lafuente (eds) Neurobiology of Interval Timing (Springer, 2014) and R. B. Ivry and W. H. Meck Curr. Op. Behav. Sci. 8; 2016) - but these are aimed at experts.

Although idiosyncratic at times, Felt Time eloquently sketches out the importance of time, both in the darkness of the lab and in the full light of everyday behaviour.

\footnotetext{
Hedderik van Rijn is professor of cognitive science and neuroscience at the University of Groningen in the Netherlands. He studies how temporal constraints influence cognitive processing, and how the brain keeps track of time.

e-mail:hedderik@van-rijn.org
}

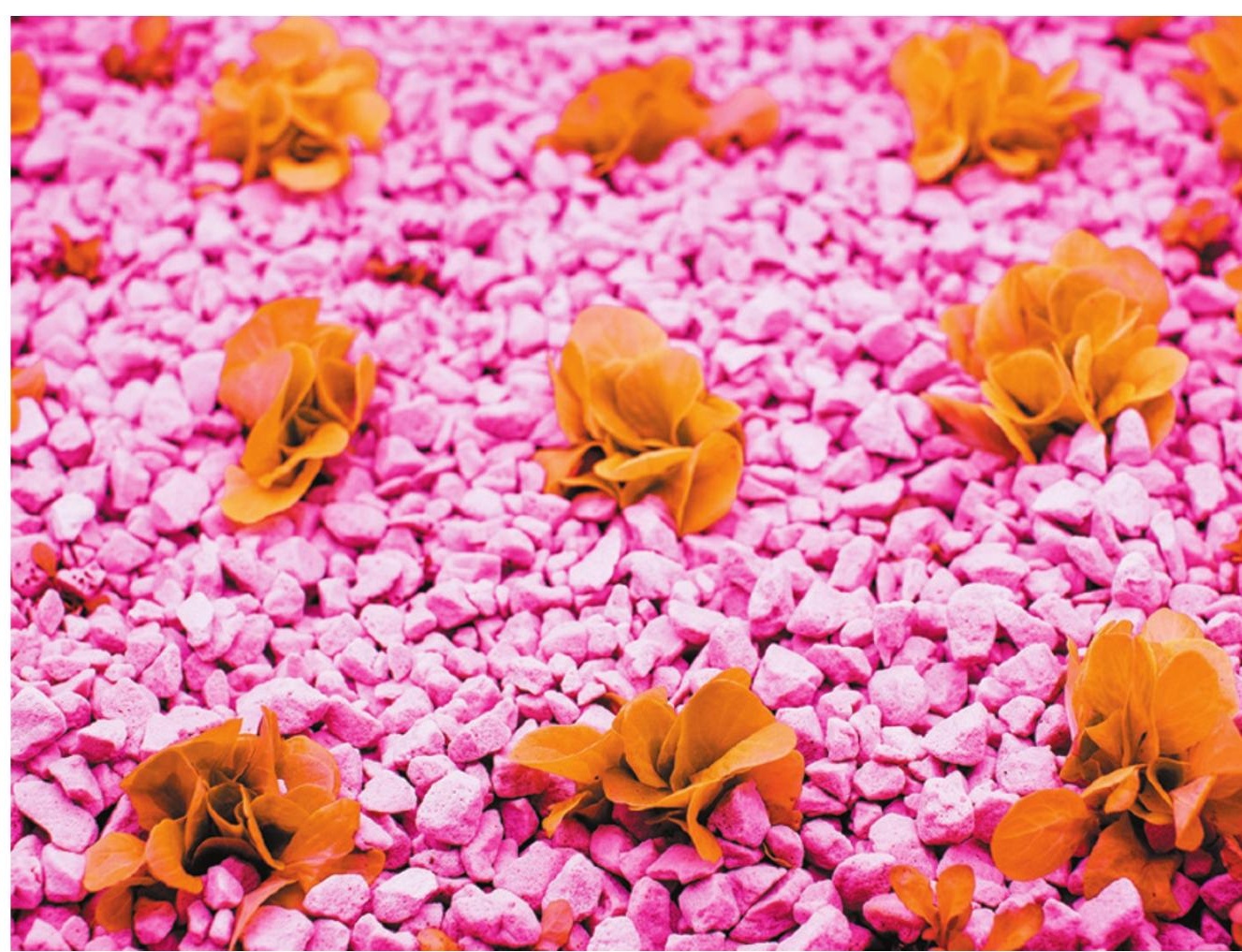

In the installation AQUAlab, plants purify water for fish, which provide fertilizer for the plants.

\title{
AGRICULTURE
}

\section{Future farming}

\section{Anthony King views video games for pigs and urban 'aquaponics' at Science Gallery Dublin's latest show.}

$\mathrm{T}$ The visible face of intensive agriculture is supermarkets bulging with vegetables, meat and milk. Yet behind the scenes, as Science Gallery Dublin's latest exhibition reveals, factory farming's reliance on energyintensive fertilizer manufacture and vast amounts of water raises big questions about sustainability. No one solution is on offer in Field Test, which is curated by the Center for Genomic Gastronomy, an artist-led global think tank devoted to imagining a more just, biodiverse food system. But visitors can feast on prototypes, research, revolutionary agronomy manifestos, innovative and imagined farm technologies and speculative cuisines. "We're asking how we can get more from less," explains acting gallery director Lynn Scarff.

Meat, for instance, is a Western penchant now spreading around the world. The Food and Agriculture Organization of the United Nations estimates that demand will increase by more than two-thirds over the next 40 years, despite sky-high costs - it takes 15,000 litres of water to produce a kilogram of beef. The curators' Farmstand Forecast
Field Test: Radical Adventures in Future Farming Science Gallery Dublin Until 5 June 2016.

looks at alternatives: attractively pack aged insect-based foods, and historical 'miracle' crops such as breadfruit and Chlorella algae. An exhibition strand dubbed 'Farm Cyborgs' features animal-husbandry innovations including Silent Herdsman, a smart collar for tracking data on bovine health. Playing With Pigs: Pig Chase is a video game for alleviating porcine boredom, designed by researchers at the HKU University of the Arts Utrecht and the Wageningen University and Research Centre, both in the Netherlands. A pig uses its snout to manipulate a virtual ball on a touch-sensitive display, while a person uses a finger to do the same on a tablet computer. The reward for moving the ball in harmony is colourful 'fireworks'.

Imagination-tickling as this is, it does not probe the central issue - demand and supply. That dilemma is framed in 'Grow House'. Does the plastinated leftover of physician Mark Post's 2013 in vitro burger, made by culturing beef cells, represent a viable solution? 
Bioartist Oron Catts thinks not. "The real price of growing meat in a lab is hidden," he notes. Muscle cells are macerated in huge quantities of fetal bovine serum obtained by slaughtering pregnant cows - half a litre of serum yields just 5 grams of meat, says Catts. His speculative Stir Fly is a sleek prototype bioreactor co-created by artist Ionat Zurr and designer Robert Foster to grow fly cells in bovine serum. The mix could be siphoned off and eaten as soup, or drained to form insect 'meat'.

Closed-loop urban agriculture systems offer a time-honoured sustainable alternative. AQUAlab, by Dublin-based agricultural start-up firm URBANFARM, harnesses aquaponics - a system in which waste from fish raised for food fertilizes salad and herbs, which in turn purify the water for the fish. (Plants and fish will eventually be harvested as a tasty proof of concept.) The 'Open Ag Lab' showcases another city-farming trend - beekeeping. In the The Dublin Honey Project, Irish black bees do their stuff in six apiaries across the city, and ecologist Jane Stout from Trinity College Dublin will be identifying pollen from the honey to determine foraging sources. Counterintuitively, the project argues that cities can be relatively clean for bees because of stringent controls on pesticides. Stout argues, too, for ecological intensification - replacing artificial inputs by optimizing ecosystem services and fostering crop diversity. In service to that vision, botanists at Trinity focus on the microbiome. For Endophyte Club, Trevor Hodkinson, Brian Murphy, Anna Kaja Hoeyer and Anindita Lahiri have extracted the microbiome of wild barley and plated the microorganisms that live in the plant out on agar plates. They show how sprinkling seeds with such endophytes can boost yields, potentially reducing fertilizer use.

The show points out that consumer choices can determine how and what is grown. 'LOCI Food Lab' is a cart peddling personalized snacks made from Irish foods, digitally selected on a tablet device using criteria such as biodiverse, traditional or delicious. My attempts yielded sweet-salty yogurt, shoots and leaves, mushroom dust and dillisk seaweed: a locavore's dream nibble.

Field Test has dug up an assortment of agricultural advances, idealistic prototypes and thought experiments. But the quirkiness on show spurs questioning even as the discoveries framed rouse hope. A coordinated solution to our hungry future remains elusive.

Anthony King is a writer based in

Dublin.

e-mail:anthonyjking@gmail.com

\section{Inching towards equality}

\author{
Athene Donald weighs up a survey of workplace \\ changes designed to avoid gender bias.
}

I n the 2013 Lean In (Knopf), Sheryl Sandberg wrote, "The promise of equality is not the same as true equality." Sandberg, chief operating officer of Facebook, purported to show women in corporate America how to succeed. I thought she put too much emphasis on the individual woman to 'man up. The book that we need to redress the indubitable gender imbalance across many sectors, including science, is one that tells organizations how to reconfigure for equality.

What Works by Iris Bohnet is intended as such a book. Sadly, I found it little more use than Lean In for working out how to transform labs and universities. Bohnet is a behavioural economist; her profession sets out to find design principles that nudge others to do the right thing, or approach it. But 'what works' in one place or situation does not necessarily work elsewhere. Take her discussion of a 1993 Indian law to increase the share of women in local government. It is hard to relate that to increasing the number of female engineering professors anywhere. By trying to cover all sectors and many nations, the book overwhelms with examples rather than solutions.

What Works is a curious mix of self-help for organizations and a semi-scholarly review. Bohnet's 70-odd pages of notes and bibliography are a voluminous resource of model and real-world studies. Her writing is accessible. Yet, I was often left puzzling over what message an admonition was meant to convey. I was particularly confused about same-sex teams versus mixed ones. Sometimes Bohnet says that homogeneity is advantageous - for example, when "a task involves coordination", which many do. But in general, she thinks that diversity is the ideal, notably when "collective problem-solving" is involved. So what do you do when you need a coordinated solution to a collective problem, such as finding the Higgs boson?

The biggest problem is the structure. Most of the book the three sections entitled 'The Problem', 'How to Design Talent Management' and 'How to Design School and Work' - mingles solutions and studies. This, I found, made it hard to extract workarounds. Each chapter

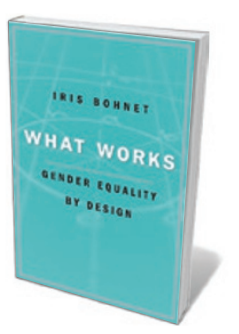

What Works: Gender Equality by Design IRIS BOHNET Belknap: 2016 ends in bullet points listing things to do, but these often seem too distilled. For example: "Prevent gender bias from having an impact: use gender-neutral designs." I am not sure that the typical head of department would be much the wiser.

There is little specifically about research and not a great deal pertaining to higher education. Most of the studies deal with politics and business. International comparators are illuminating in an abstract way, but not when it comes to practical advice for a principal investigator or dean. No explicit help is provided for drafting a job advertisement that demands excellence without putting off the less self-confident; nor is there anything on constructing departmental policies to encourage inclusivity among individuals competing for resources. Many of the organizations that Bohnet discusses have tens of thousands of employees. So their strategies for recruitment and promotion are very different from those for hiring a single tenure-track professor.

That said, readers will learn about some approaches that have worked or failed. I found the idea of reframing job specifications useful: for instance, offering flexibility as the norm that anyone can ask for, rather than that tricky thing that pesky women want. Another simple, but key, step is to purge gendered language from all advertisements. For instance, by saying that salaries are negotiable, the advertisement can help both men and women to feel comfortable opening that dialogue; without it, many women are more reticent, and the gender pay gap opens up.

But I didn't find drawing out the three easy wins for my university very easy. Quotas are helpful, unless there is a backlash because of the idea that less-well-qualified people from under-represented groups have been allowed in. Role models are important, except when people decide 'problem solved' and go back to not thinking about them at all. The book is pervaded with caveats - and justifiably so, because equality is a hard problem to solve.

Bohnet hasn't cracked it because her advice is too broad. But her examples do embody an important point: the path to equality lies in retooling our institutions, not ourselves.

Athene Donald is professor of experimental physics and former gender-equality champion at the University of Cambridge, UK. She is master of Churchill College, Cambridge. e-mail:amd3@cam.ac.uk 